\title{
Designing reinforced concrete slabs under fire condition
}

\author{
Michat Maciąg ${ }^{1}$, and Szymon Spodzieja ${ }^{1, *}$, \\ ${ }^{1}$ Warsaw University of Technology, Faculty of Civil Engineering, Institute of Building Engineering, \\ Poland
}

\begin{abstract}
In this article the capacity of reinforced concrete slabs of thickness larger than $15 \mathrm{~cm}$ was calculated with Isotherm 500 Method. For designed elements were analysed the support and span zone. There have been proposed tables for designers, on which basis it is possible to design slab of demanded fire capacity.
\end{abstract}

\section{Introduction}

The designers has an obligation to ensure appropriate construction capacity in case of a fire. For many years requirements for reinforced concrete structures have been satisfied by appropriate dimensions of designed elements. Usually it means required length from the mass centre of the main rebar to concrete slab face and cross-section thickness. Since E2 was introduced it became possible to design reinforced concrete elements using methods different than tabular.

E2 enables additionally:

- Simplified calculating models for selected structure elements (eg. zone method)

- Advanced calculating models (most frequently FEM)

In the article the capacity of reinforced concrete slabs have been calculated using Isotherm 500 Method. It enables to design any selected element in the structure. The aim of this work is calculation of ultimate capacities in span and support zone of reinforced concrete slabs in typical column-slab structures in case of fire.

\section{Assumptions}

The Isotherm 500 Method is simplified methods of designing reinforced concrete elements in case of fire. This method is based mainly on reduction of concrete cross-section and steel plasticity limit modification depending on temperature in rebar. Additional restrictions assumed by authors are:

- Analysis of slabs reinforced with steel $f_{y k}=500 \mathrm{MPa}$ with appropriate plasticity that ensures strain not smaller than $2 \%$ in temperatures higher than $200^{\circ} \mathrm{C}$,

- Concrete with characteristic compression capacity in normal conditions smaller than $50 \mathrm{MPa}$,

\footnotetext{
* Corresponding author: $\underline{\text { s.spodzieja@il.pw.edu.pl }}$
} 
- The destruction of elements in case of concrete crush in fire was admitted,

- It was assumed that floor layers ensure appropriate precaution in case of fire "from above". In calculations assumed slab heating only from below,

- Load in case of fire was assumed according to EC using load reduction coefficient $n_{f}$.

- Fire standard function was assumed according to EC2.

\subsection{Definitions}

For section capacity analysis were used dimensionless values:

$$
\begin{aligned}
& m_{R d}=\frac{M_{R d}}{f_{c d} b d^{2}}-\text { dimensionless section capacity for bending, } \\
& \alpha=\xi_{e f f}=\frac{x_{e f f}}{d}=\frac{A_{s} f_{y d}}{b d f_{c d}}-\text { reinforcement level, } \\
& \sigma_{s, f i}=p f_{y d, f i} \text { - reinforcement stresses in case of fire, } \\
& p \text { - level of reinforcement usage in case of, } p \in(0,1\rangle, \\
& \gamma_{c} \text { - partial concrete coefficient in normal conditions }(\mathrm{EC} 2=1,4), \\
& \gamma_{s} \text { - partial steel coefficient in normal conditions }(\mathrm{EC} 2=1,15) .
\end{aligned}
$$

\subsection{Load reduction coefficient under fire conditions $-\boldsymbol{n}_{\boldsymbol{f}}$}

Fire load belongs to exceptional load condition. To specify structure load exposed to fire we often use relation of calculation load under fire conditions to calculation load in normal conditions.

According to EC2 recommendations, we assumed $n_{f}=0,7$. For designers it is safe side assumption. It is worth pointing out that taking lower values of reduction coefficients can raise fire capacity class of designing structure. Lower values have been considered in final tables. (Table 1-2).

\subsection{Temperature in reinforcement and reduction of section}

For calculating the capacity we need to determine the temperature in the rebar. Using the results of heated reinforced concrete slabs numerical simulation [2], we obtained temperature values in extended rebar. The temperature in concrete slab reinforced section depends on the distance value from the main rebar mass centre to the concrete slab face, as it is illustrated below (Figure 1)

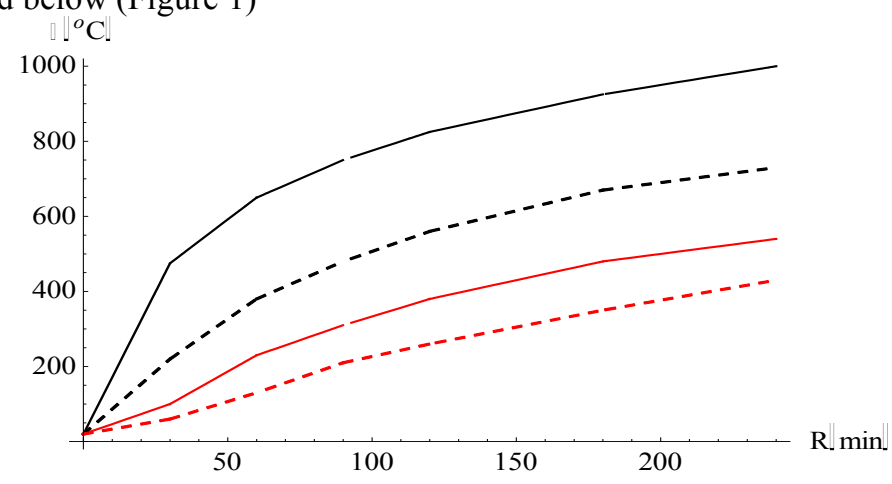


Fig. 1. Relation of temperature in rebar from fire duration for different distances of heated concrete slab face. (from bottom 2,3,4,5 cm)[2]

In paper [2] Isotherm 500 position in reinforced concrete slabs were recommended. It turned out that for slabs thicker than $h>15 \mathrm{~cm}$ Isotherm 500 position does not depend on the element thickness (Figure 2).

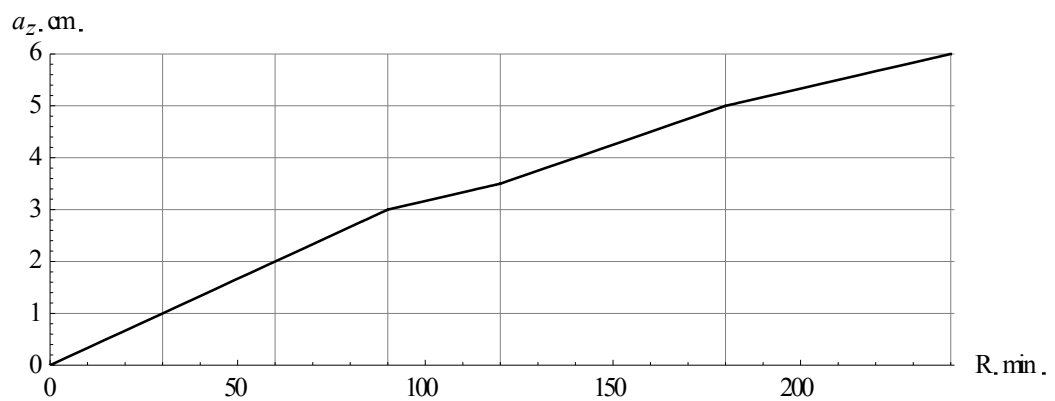

Fig. 2. Relation of Isotherm 500 position; relation $a_{z}(R)[2]$

Extended rebar in the support zone does not change significantly its temperature because of floor layer precaution from above and through reinforced concrete slab size from below. Additionally in the support zone there is rebar to counter the perforation. Using the numerical simulations [2], it was assumed that on its length the temperature does not reach $500^{\circ} \mathrm{C}$ and the steel plasticity limit does not change. Because of that in support zone the influence of fire to slab rebar was omitted.

\subsection{Steel strains}

Because of the significant steel strains increase caused by high temperature, maximal height of the compression zone decreases. However for high reinforcement level under fire conditions the destruction of cross-section is possible because of worn concrete capacity. Such situation cannot be omitted, because it could result in capacity structure inestimation. With temperature increase maximal plastic strains change because of reinforcement load. Assuming steel strains limit according to EC2 and omitting strains caused by termic can cause fire capacity overvaluation. To the steel strain limit was added strains caused by temperature:

$$
\varepsilon_{s, f i, \theta, \lim }=\varepsilon_{s, \theta}+\varepsilon_{s, f i, \lim }
$$

\subsection{Coefficient reducing steel and concrete capacity}

According to Isotherm 500 we did not assume coefficient reducing concrete resistance for compression. Capacity decrease is achieved through reducing section according to Isotherm 500 trajectory under fire conditions. For local temperature $\theta<500^{\circ} C$ we assumed $\mathrm{f}_{\mathrm{cd}, \mathrm{fi}}=\mathrm{f}_{\mathrm{ck}}$ and for other $\mathrm{f}_{\mathrm{cd}, \mathrm{fi}}=0$.

Decrease of reinforcement capacity was found using ks, $\theta$ coefficient, which reduce characteristic steel plasticity limit $f_{y d, f i}=k_{s, \theta} f_{y k}$. According to EC2, coefficient $k_{s, \theta}$ values was assumed by Table 1. 
Table 1. Coefficient $k_{s, \theta}$ in relation to temperature

\begin{tabular}{|c|c|c|c|c|c|c|c|c|c|}
\hline $\mathrm{T}\left[{ }^{\circ} \mathrm{C}\right]$ & 20 & 100 & 200 & 300 & 400 & 500 & 600 & 700 & 800 \\
\hline $\mathrm{k}_{\mathrm{s}, \theta}$ & 1,00 & 1,00 & 1,00 & 1,00 & 1,00 & 0,78 & 0,47 & 0,23 & 0,11 \\
\hline
\end{tabular}

Table 1 can be used for cold rolled steel with appropriate plasticity that can reach strain more than $2 \%$ in temperature higher than $200^{\circ} \mathrm{C}$.

As it was mentioned concrete crush were taken under consideration. In such situations steel will not reach limit strain, so strain will be smaller than plasticity limit [1]. Strain value in destruction moment were determined using chart below:

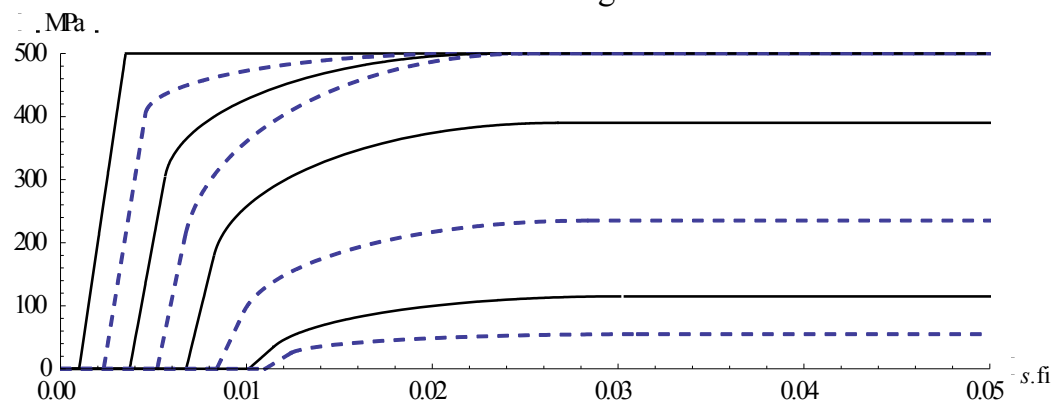

Fig. 3. Relation $\varepsilon(\sigma)$ to different steel reinforcement temperatures (Continuous lines from the top $100 / 300 / 500 / 700^{\circ} \mathrm{C}$, hidden lines from the top $-200 / 400 / 600 / 800^{\circ} \mathrm{C}$ ) [1]

\section{Span zone}

Because of small sheer forces in middle zone it was omitted. Bending capacity was determined for single reinforced slab using simplified concrete section model. In dimensionless values moment capacity can be found with formula [3]:

$$
m_{R d}=\alpha\left(1-\frac{\alpha}{2}\right)
$$

It was assumed that section was designed for $100 \%$ capacity, so $m_{E d}=m_{R d}$. After force reduction with coefficient " $n_{f}$ " dimensionless load under fire condition equals: $m_{E d, f i}=n_{f} m_{E d}$

Bending capacity under fire condition equals:

$$
m_{R d, f i}=\alpha \gamma_{s} p k_{s, \theta}\left(1-\frac{1}{2} \frac{\gamma_{s}}{\gamma_{c}} p k_{s, \theta}\right)
$$

To determine steel capacity value such equations were used:

$$
\left\{\begin{array}{c}
\varepsilon_{s, f i}+\varepsilon_{s, \theta}=\frac{\varepsilon_{c u}(1-\xi)}{\xi} \\
\sigma_{s, f i}=p f_{y d, f i} \\
\xi_{e f f, f i}=\alpha \frac{\gamma_{s}}{\gamma_{c}} p k_{s, \theta} \\
\sigma_{s, f i}=f\left(\varepsilon_{s, f i}+\varepsilon_{s, \theta}\right)
\end{array}\right.
$$

After solving this equations (3) for different distances from mass centre of the main rebar to concrete slab face (a), capacity charts for $\mathrm{a}=2 \mathrm{~cm}, 3 \mathrm{~cm}, 4 \mathrm{~cm}, 5 \mathrm{~cm}$ were reached. 
On the horizontal axis are dimensionless reinforcement levels and on vertical dimensionless capacity.

If capacity chart is over maximum load chart it means that this section has minimum this fire resistance.

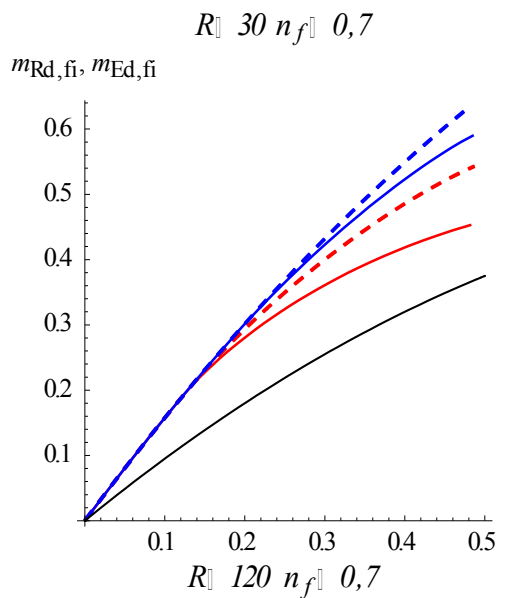

$m_{\mathrm{Rd}, \mathrm{fi}}, m_{\mathrm{Ed}, \mathrm{fi}}$

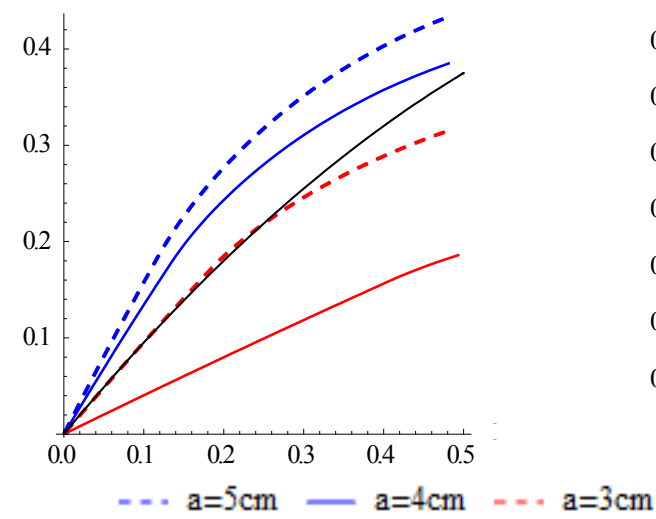

$R \rrbracket 60 n_{f} \llbracket 0,7$

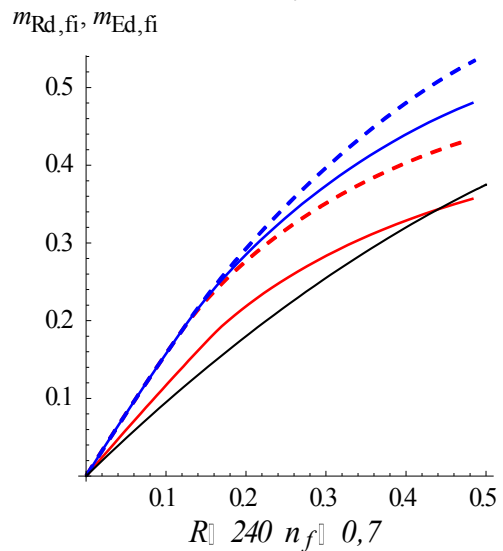

$m_{\mathrm{Rd}, \mathrm{fi}}, m_{\mathrm{Ed}, \mathrm{fi}}$

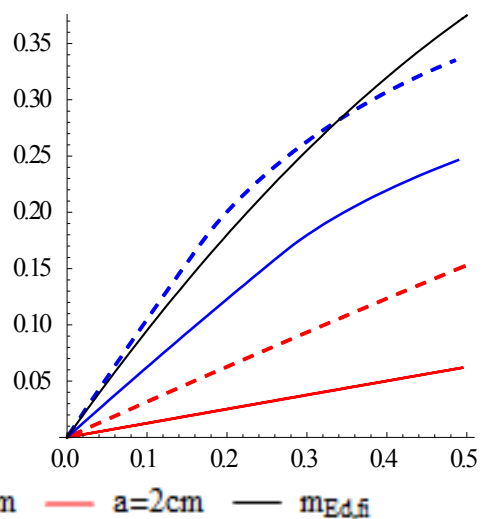

Fig. 4. Capacities under fire condition for $\mathrm{a}=2,3,4,5 \mathrm{~cm}$ and $n_{f}=0,7$

\section{Support zone}

In the support zone bending and punching shear capacity were checked. For analysis were taken $\mathrm{d}=12 \mathrm{~cm}, 15 \mathrm{~cm}, 22 \mathrm{~cm}$, where $\mathrm{d}$ is useful height of the section.

\subsection{Bending capacity}

Bending capacity under normal conditions is the same as in span zone. In support zone there is no steel capacity reduction, so the section capacity can be found from:

$$
m_{R d, f i}=\alpha \gamma_{s} p\left(1-\frac{a_{z}}{d}-p \frac{\alpha}{2} \frac{\gamma_{s}}{\gamma_{c}}\right)
$$


" $p$ " can be found from following equations:

$$
\left\{\begin{array}{c}
\varepsilon_{s, f i}=\frac{\varepsilon_{c u}\left(1-\frac{a_{z}}{d}-\xi\right)}{\xi} \\
\sigma_{s, f i}=p f_{y d, f i} \\
\xi_{e f f, f i}=\alpha \frac{\gamma_{s}}{\gamma_{c}} p \\
\sigma_{s, f i}=E \varepsilon_{s, f i}
\end{array}\right.
$$

After solving the equations capacity charts were obtained (Figure 5). Interpretation is the same as in point 3

\section{$R 30$}

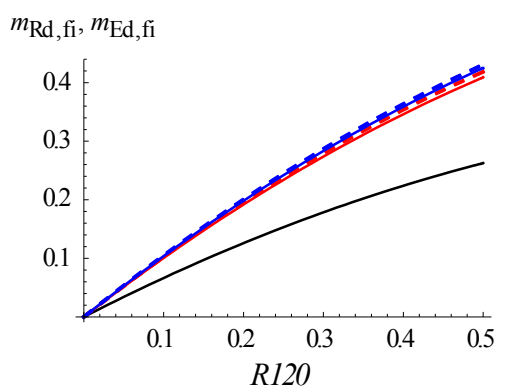

$m_{\mathrm{Rd}, \mathrm{fi}}, m_{\mathrm{Ed}, \mathrm{fi}}$

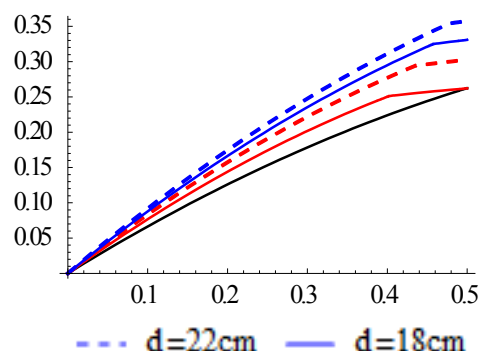

$R 60$

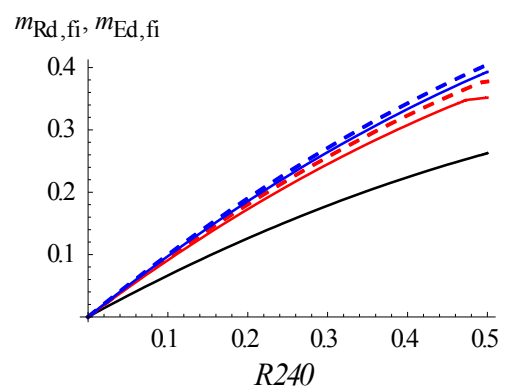

$m_{\mathrm{Rd}, \mathrm{fi}}, m_{\mathrm{Ed}, \mathrm{fi}}$

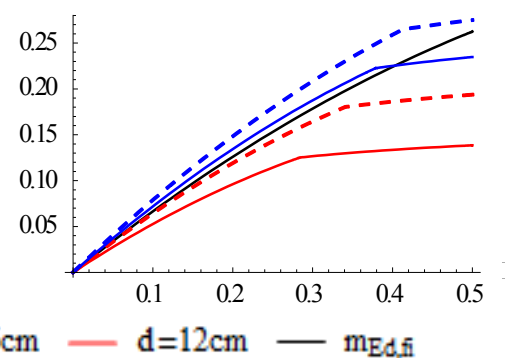

Fig. 5. Capacities under fire condition for $d=12,16,18,22 \mathrm{~cm}$ and $n_{f}=0,7$.

\subsection{Punching shear capacity}

Because reinforcement that prevents punching shearing has the average temperature lower than $400^{\circ} \mathrm{C}$ in this part were checked only slabs without them. According to [5] if there are no prestressed forces, punching shear capacity under fire conditions equals:

$$
V_{R d, c, f i}=\frac{1}{\beta} \frac{0,18}{1}\left(1+\sqrt{\frac{200}{d-a_{z}}}\right) \sqrt[3]{100 \rho_{l} f_{c k}}\left(d-a_{z}\right) u_{f i}
$$

Control circumference depends from dimensions of a column punching shearing the slab. The bigger column circumference the smaller the effect of the slab thickness. Which is why small circular column with diameter $10 \mathrm{~cm}$ were assumed. Then $u=2 \pi\left(5+2\left(d-a_{z}\right)\right)$. 
Because of complicated formulas in this point dimensionless values were not used. Instead proportion $V_{R d, c, f i} / V_{E d, f i}$ were checked. It was showed than for this support type always fire capacity R120 is reached. Other results are presented in Tab. 4.

\section{Conclusion}

Fire capacity calculated according to Isotherm 500 Method is similar to tabularise method given in EC [6]. More precise tables 2-4 containing more parameters were proposed. Using them designer can take under consideration reinforcement level " $\alpha$ ", load reduction coefficient under fire conditions " $n_{f} "$ and distances from mass centre of the main rebar to concrete slab face " $a$ ".

Table 2. Fire capacity for span zone

\begin{tabular}{|c|c|c|c|c|c|c|c|c|c|c|c|c|c|}
\hline \multicolumn{7}{|c|}{ Fire capacity for $\mathrm{a}=2 \mathrm{~cm}$} & \multicolumn{7}{|c|}{ Fire capacity for $\mathrm{a}=3 \mathrm{~cm}$} \\
\hline \multirow[t]{2}{*}{$n_{f}$} & \multicolumn{6}{|c|}{ maximum $\alpha$} & $n_{f}$ & \multicolumn{6}{|c|}{ maximum $\alpha$} \\
\hline & R30 & R60 & $\mathrm{R} 90$ & $\mathrm{R} 120$ & $\mathrm{R} 180$ & $\mathrm{R} 240$ & & R30 & R60 & R90 & R120 & R180 & $\mathrm{R} 240$ \\
\hline 0.7 & 0.5 & 0.44 & - & 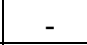 & - & 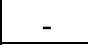 & 0.7 & 0.5 & 0.5 & 0.5 & 0.092 & - & - \\
\hline 0.6 & 0.5 & 0 & - & - & - & - & 0.6 & 0.5 & 0.5 & .5 & 0.494 & - & - \\
\hline 0.5 & 0.5 & 0.5 & 0.006 & - & - & - & 0.5 & 0.5 & 0.5 & 0. & 0.5 & - & - \\
\hline 0.4 & 0.5 & 0.5 & 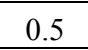 & - & - & - & 0.4 & 0.5 & 0.5 & 0. & 0.5 & 0.336 & - \\
\hline 0.3 & 0.5 & 0.5 & 0.5 & 0.122 & - & - & 0.3 & 0.5 & 0.5 & 0.5 & 0.5 & 0.5 & - \\
\hline \multicolumn{7}{|c|}{ Fire capacity for $\mathrm{a}=4 \mathrm{~cm}$} & \multicolumn{7}{|c|}{ Fire capacity for $\mathrm{a}=5 \mathrm{~cm}$} \\
\hline$n_{f}$ & \multicolumn{6}{|c|}{ maximum $\alpha$} & $n_{f}$ & \multicolumn{6}{|c|}{ maximum $\alpha$} \\
\hline & R30 & R60 & R90 & R120 & R180 & R240 & & R30 & R60 & R90 & R120 & R180 & $\mathrm{R} 240$ \\
\hline 0.7 & 0.5 & 0.5 & 0.5 & 0 & - & 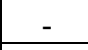 & 0.7 & 0.5 & 0.5 & 0.5 & .5 & 0.5 & 0.34 \\
\hline 0.6 & 0.5 & 0.5 & 0.5 & 0.5 & 0.401 & - & 0.6 & 0.5 & 0.5 & 0.5 & 0.5 & 0.5 & 0.5 \\
\hline 0.5 & 0.5 & 0.5 & 0.5 & 0.5 & 0.5 & - & 0.5 & 0.5 & 0.5 & 0.5 & 0.5 & 0.5 & 0.5 \\
\hline 0.4 & 0.5 & 0.5 & 0.5 & 0.5 & 0.5 & 0.5 & 0.4 & 0.5 & 0.5 & 0.5 & 0.5 & 0.5 & 0.5 \\
\hline 0.3 & 0.5 & 0.5 & 0.5 & 0.5 & 0.5 & 0.5 & 0.3 & 0.5 & 0.5 & 0.5 & 0.5 & 0.5 & 0.5 \\
\hline
\end{tabular}

Table 3. Fire capacity for support zone

\begin{tabular}{|c|c|c|c|c|c|c|c|c|c|c|c|c|c|}
\hline \multicolumn{7}{|c|}{ Fire capacity for $\alpha<0.1$} & \multicolumn{7}{|c|}{ Fire capacity for $\alpha<0.2$} \\
\hline \multirow[t]{2}{*}{$n_{f}$} & \multicolumn{6}{|c|}{ minimum d $[\mathbf{c m}]$} & $n_{f}$ & \multicolumn{6}{|c|}{ minimum d $[\mathbf{c m}]$} \\
\hline & $\mathrm{R} 30$ & R60 & R90 & $\mathrm{R} 120$ & $\mathrm{R} 180$ & $\mathrm{R} 240$ & & $\mathrm{R} 30$ & R60 & R90 & $\mathrm{R} 120$ & $\mathrm{R} 180$ & $\mathrm{R} 240$ \\
\hline 0.7 & - & - & - & - & 13.2 & 15.8 & 0.7 & - & - & - & - & 13.6 & 16.3 \\
\hline 0.6 & - & - & - & - & - & 13 & 0.6 & - & - & - & - & - & 13.4 \\
\hline 0.5 & - & - & - & - & - & - & 0.5 & - & - & - & - & - & - \\
\hline 0.4 & - & - & - & - & - & - & 0.4 & - & - & - & - & - & - \\
\hline 0.3 & - & - & - & - & - & - & 0.3 & - & - & - & - & - & - \\
\hline \multicolumn{7}{|c|}{ Fire capacity for $\alpha<0.3$} & \multicolumn{7}{|c|}{ Fire capacity for $\alpha<0.5$} \\
\hline$n_{f}$ & \multicolumn{6}{|c|}{ minimum $\mathbf{d}[\mathrm{cm}]$} & $n_{f}$ & \multicolumn{6}{|c|}{ minimum $d[\mathbf{c m}]$} \\
\hline & $\mathrm{R} 30$ & R60 & R90 & $\mathrm{R} 120$ & $\mathrm{R} 180$ & $\mathrm{R} 240$ & & $\mathrm{R} 30$ & R60 & R90 & $\mathrm{R} 120$ & $\mathrm{R} 180$ & $\mathrm{R} 240$ \\
\hline 0.7 & - & - & - & - & 14 & 16.7 & 0.7 & - & - & - & 12.1 & 17.2 & 20.7 \\
\hline 0.6 & - & - & - & - & - & 13.9 & 0.6 & - & - & - & - & 14.4 & 17.3 \\
\hline
\end{tabular}




\begin{tabular}{|c|c|c|c|c|c|c|c|c|c|c|c|c|c|}
\hline 0.5 & - & - & - & - & - & 12.1 & 0.5 & - & - & - & - & 12.2 & 14.7 \\
\hline 0.4 & - & - & - & - & - & - & 0.4 & - & - & - & - & - & 12.6 \\
\hline 0.3 & - & - & - & - & - & - & 0.3 & - & - & - & - & - & - \\
\hline
\end{tabular}

Table 4. Fire capacity for punching shear

\begin{tabular}{|c|c|c|c|c|c|c|}
\hline $\boldsymbol{n}_{\boldsymbol{f}}$ & \multicolumn{6}{|c|}{ minimum d[cm] } \\
\hline & R30 & R60 & R90 & R120 & R180 & R240 \\
\hline 0.7 & - & - & - & - & 16 & 19.4 \\
\hline 0.6 & - & - & - & - & 13.4 & 16.3 \\
\hline 0.5 & - & - & - & - & - & 13.8 \\
\hline 0.4 & - & - & - & - & - & - \\
\hline
\end{tabular}

To make using charts easier tables 2-4 were presented. In tables maximum reinforcement level for which slab has given fire capacity is tabularised. Since taking $n_{f}=0,7$ is a restrict assumption in tables other values of $n_{f}$ are given.

Tables 2-4 confirm the values that are reported to be safe in tabular form in EC2. Additionally, the use of the Isotherm 500 in the design of reinforced concrete slabs allows to increase the fire resistance class by increasing the reinforcement level $\alpha$, which the EC2 table method has not previously allowed.

Increasing the ceiling reinforcement level $\alpha$ to increase fire capacity seems to be justified in the case of R30 / R60 / R90. Achieving higher fire classes by increasing the cross-sectional area of reinforcement seems economically unprofitable.

\section{References}

1. M. Abramowicz, R. Kowalski, Subjected to Tension and High Temperature, Application of Structural Fire Design, Prague, Czech Republic, 19-20 February (2009)

2. R. Kowalski, Computational assessment of load bearing capacity of reinforced concrete elements in a fire situation, 149 (Oficyna Wydawnicza Politechniki Warszawskiej, Tomy Prace Naukowe Politechniki Warszawskiej, Budownictwo, 2008)

3. M. Knauff, Calculation of reinforced concrete structures according to Eurokod 2 (PWN Scientific Publisher, 2015)

4. K. Hertz, Structures in fire - proceeding of first international workshop, 283-292 (2000)

5. PN-EN 1992-1-1-2008: Designing concrete structures - Part 1-1: General rules and rules for buildings

6. PN-EN 1992-1-2-2008: Designing concrete structures - Part 1-2: General rules Designing due to fire conditions 